\title{
The Kuznets Curve: What Happens After the Inverted-U?
}

\author{
John A. List and Craig A. Gallet*
}

\begin{abstract}
Recent research has posited that, in advanced economies, there is a positive correlation between income inequality and development. Using a new unbalanced panel dataset for 71 countries from 1961 to 1992 , we present evidence that supports this conjecture. Although many factors may be contributing to this renewed positive relationship between growth and inequality, one plausible explanation rests on the shift away from a manufacturing base towards a service base in most advanced economies.
\end{abstract}

\section{Introduction}

Research on factors affecting income distribution remains a cornerstone of the development literature. Following Kuznets' (1955) claim that income inequality and economic growth are related to each other via an inverted-U curve (hereafter labeled the Kuznets curve), numerous studies (e.g., Cline, 1975; Cromwell, 1977; Papanek and Kyn, 1986; Ram, 1995; Jha, 1996; Dawson, 1997) have regressed measures of income inequality on per capita income and per capita income-squared, generally finding support for Kuznets' hypothesis. This finding is consistent with industrial development initially leading to increased income inequality, and subsequently, after a threshold level of income is reached, income inequality begins to lessen with further increases in income. Cross-sectionally, these findings imply that lower-developed (higher-developed) countries tend to fall along the positively (negatively) sloped region of the Kuznets curve.

Several criticisms have been levied against the traditional approaches used to identify the Kuznets curve. First, since studies typically use either cross-sectional data from several countries or time-series data from a single country, important intracountry and/or intercountry variations are often ignored. Second, given recent evidence (Amos, 1988; Bishop et al., 1991; Ram, 1991; Katz and Murphy, 1992; Bound and Johnson, 1992; Ravallion, 1995; Partridge et al., 1996; Tribble, 1996; Ram, 1997) that, for very high income levels, the relationship between income inequality and per capita income reverts back to positive, a quadratic specification of the Kuznets curve fails to provide the necessary flexibility if the sample includes a mix of developed and underdeveloped countries. For example, to account for the prospect of increasing income inequality, Tribble (1996) estimates a cubic specification of the Kuznets curve for the US economy, where his time-series results indicate that for per capita income levels beyond $\$ 11,000$ the US is on the second positively sloped region of the Kuznets curve.

Our study addresses the limitations of previous approaches by using time-series of cross-sectional data from a large number of countries to estimate an alternative specification of the Kuznets curve. Specifically, we use a new panel dataset of 71 countries, which includes a mix of lower-developed and higher-developed countries, over the 1961-92 period to estimate a more flexible form of the Kuznets specification. By doing so, we are able to analyze a myriad of countries over a lengthy period to assess

\footnotetext{
* List, Gallet: College of Business, PO Box 161400, University of Central Florida, Orlando, FL 32816-1400, USA. Tel: 407-823-3720; Fax: 823-3269; E-mail: craig.gallet@bus.ucf.edu.
} 
whether or not the relationship between income inequality and per capita income for higher-developed countries has reverted back to positive.

Our results confirm that a positive correlation characterizes the current relationship between income inequality and development for more advanced economies. As such, our results provide cross-country support for recent time-series evidence which suggests that developed economies (such as the US) are in a period of increasing income inequality. Although numerous factors may be playing a role in the renewed positive relationship between development and inequality, one plausible explanation rests on the shift away from a manufacturing base towards a service base in most advanced economies. Similar to Kuznets' (1955) original theory, therefore, this population shift represents a theoretical basis for the current distribution change taking place in more advanced economies.

Section 2 presents the empirical model and our estimation results. Section 3 concludes the paper with summary comments.

\section{Empirical Model and Results}

\section{Empirical Model}

In estimating the Kuznets reduced-form relationship, we employ the GINI coefficient as the measure of income inequality. ${ }^{1}$ Our econometric representation of the Kuznets curve is given by

$$
G_{i t}=\alpha_{i}+\beta X_{i t}+\Phi T+\sum_{i=1}^{13} C_{i} D_{i}+\varepsilon_{i t}, \quad i=1,2, \ldots, N, t=1,2, \ldots, T,
$$

where $G_{i t}$ is the GINI coefficient for country $i$ at time $t, \beta$ are the estimated parameters of interest, $X_{i t}$ includes real per capita income (in international dollars at 1985 prices), real per capita income-squared, and real per capita income-cubed, $\alpha_{i}$ are the estimated fixed or random effects, $\Phi$ is the coefficient of time $(T=1961,1962, \ldots$, 1992), $D_{i}$ are corrective dummy variables for the differences in definitions of the GINI coefficient (with coefficient $C_{i}$ ), and $\varepsilon_{i t}$ is the contemporaneous error term. Since data for most underdeveloped countries are relatively scarce and scattered, whereas developed countries have complete or near-complete panels, the sample consists of 71 countries across sporadic years between 1961 and 1992, and hence equation (1) forms an unbalanced panel. ${ }^{2}$ Table 1 contains descriptive statistics for the variables of interest.

Table 1. Descriptive Statistics ${ }^{\mathrm{a}, \mathrm{b}}$

\begin{tabular}{lcccc}
\hline Variable & Mean & Standard deviation & Minimum & Maximum \\
\hline Gini & 0.38 & 0.09 & 0.13 & 0.64 \\
$\begin{array}{l}\text { Per capita income } \\
\text { (1985ID) }\end{array}$ & 4,536 & 4,434 & 418 & 18,095 \\
& & & \\
& & Quartiles of per capita income & \\
& $(1 \mathrm{st})$ & $(2 \mathrm{nd})$ & $(3 \mathrm{rd})$ & $(4 \mathrm{th})$ \\
& 4,837 & 9,256 & 13,676 & 18,095 \\
\hline
\end{tabular}

\footnotetext{
a Sample includes data from 71 countries over the 1961-92 period; sample size is 892 .

${ }^{\mathrm{b}}$ Per capita income is in real international dollar terms (Heston et al., 1995).
} 
Estimates of equation (1) are obtained using pooled ordinary least squares (OLS), fixed-effects panel data, and random-effects panel data models. Both fixed- and random-effects panel data approaches control for unmeasured heterogeneity that pooled OLS ignores. Random-effects estimates of equation (1) yield coefficients that are not conditioned on unmeasured country effects, whereas fixed-effects estimates yield coefficients that are conditioned on the unmeasured characteristics. Hence, fixedeffects estimates are inefficient since they consider only within-country variation. Yet, if the country effects are correlated with income levels, random-effects estimates are biased and inconsistent, while the within estimator remains unbiased and consistent. Consequently, in order to check for unbiasedness and consistency, Hausman (1978) tests are done when comparing estimates from fixed- and random-effects models.

\section{Empirical Results}

Table 2 provides results from the estimation of equation (1) via pooled OLS, panel with fixed effects, and panel with random effects. ${ }^{3}$ An initial consideration is determining which of the three models is the most appropriate. Homogeneity of the country effects is rejected at the $1 \%$ level of significance for both panel data models (fixed effects: $F=17.7$; random effects: $L M=1459$ ), suggesting pooled OLS estimates are inefficient at best. This result is particularly interesting since it refutes the presumption that a universal path of economic development exists. Rather, it implies that each

Table 2. Panel Data Estimates for Determinants of Gini Coefficient ${ }^{\mathrm{a}, \mathrm{b}, \mathrm{c}}$

\begin{tabular}{|c|c|c|c|}
\hline Independent variable & Pooled OLS & Fixed effects & Random effects \\
\hline Constant & $\begin{array}{c}2.36^{*} \\
(3.3)\end{array}$ & - & $\begin{array}{r}1.54 * \\
(2.6)\end{array}$ \\
\hline Income & $\begin{array}{c}0.54 \mathrm{E}-4^{*} \\
(9.9)\end{array}$ & $\begin{array}{c}0.84 \mathrm{E}-5 \\
(1.1)\end{array}$ & $\begin{array}{c}0.42 \mathrm{E}-5 \\
(0.6)\end{array}$ \\
\hline Income-squared & $\begin{array}{c}-0.84 \mathrm{E}-8^{*} \\
(-10.6)\end{array}$ & $\begin{array}{c}-0.16 \mathrm{E}-8^{* * * *} \\
(-1.7)\end{array}$ & $\begin{array}{c}-0.16 \mathrm{E}-8^{* * * *} \\
(-1.7)\end{array}$ \\
\hline Income-cubed & $\begin{array}{c}0.33 \mathrm{E}-12^{*} \\
(10.4)\end{array}$ & $\begin{array}{c}0.71 \mathrm{E}-13^{* *} * \\
(2.0)\end{array}$ & $\begin{array}{c}0.74 \mathrm{E}-13^{* *} \\
(2.2)\end{array}$ \\
\hline Year & $\begin{array}{c}-0.11 \mathrm{E}-2^{*} \\
(-2.9)\end{array}$ & $\begin{array}{c}-0.79 \mathrm{E}-3^{* * *} \\
(-2.4)\end{array}$ & $\begin{array}{c}-0.56 \mathrm{E}-3^{* * *} \\
(-2.0)\end{array}$ \\
\hline $\begin{array}{l}F\left(\alpha_{i}=0\right) \\
(\mathrm{df})\end{array}$ & - & $\begin{array}{c}17.7^{*} \\
(70,816)\end{array}$ & - \\
\hline $\begin{array}{l}L M \\
\text { (df) }\end{array}$ & - & - & $\begin{array}{c}1,459^{*} \\
(1)\end{array}$ \\
\hline $\begin{array}{l}\text { Hausman } \\
\text { (df) }\end{array}$ & - & - & $\begin{array}{l}1.2 \\
(5)\end{array}$ \\
\hline$R^{2}$ & 0.12 & 0.65 & - \\
\hline Adj. $R^{2}$ & 0.12 & 0.62 & - \\
\hline Turning point-down (1985ID) & 4,245 & 3,257 & 1,487 \\
\hline Turning point-up (1985ID) & 12,816 & 11,981 & 12,115 \\
\hline Sample size & 892 & 892 & 892 \\
\hline
\end{tabular}

\footnotetext{
${ }^{a}$ Dependent variable is the Gini coefficient.

${ }^{\mathrm{b}} t$-statistics in parentheses.

${ }^{\mathrm{c}}$ Estimates for the corrective dummies are excluded, but are available upon request.

*Significant at 0.01 level; ** at 0.05 level; *** at 0.10 level.
} 
country's growth path is unique. Also, since the Hausman statistic $\left(\chi^{2}(5)=1.2\right)$ fails to reject the null hypothesis of orthogonality at conventional levels of significance, the more efficient random-effects estimates remain consistent and unbiased. Thus, the random-effects model appears apropos from the statistical tests.

Table 2 shows that parameter estimates from all three regression models support Kuznets' hypothesis. Namely, over ranges of development, increases in per capita income initially lead to greater income inequality, yet after a critical per capita income level further increases in per capita income lead to less income inequality. Yet, consistent with recent time-series evidence, we also find that for high per capita income levels, beyond the second quartile in all three estimated versions, the relationship between income inequality and per capita income reverts back to positive. This is highlighted in Figure 1, which plots the raw data and provides a representation of the three regions of the Kuznets curve for the random-effects model. Region I encompasses those countries with per capita incomes below 1,487 (1985 international dollars), region II encompasses middle-income countries (1,487-12,115), and region III encompasses more advanced economies. Furthermore, to supplement Figure 1, we provide in Table 3 a categorization of the countries that fall into each of the three regions of the Kuznets curve; and as indicated in Table 3, for example, the US is currently on the second positively sloped region of the Kuznets curve, implying that income inequality in the US is increasing. This result is consistent with findings from previous studies of US income inequality (e.g., Amos, 1988; Ram, 1991; Partridge et al., 1996; Tribble, 1996). However, since the majority of the countries in our sample fall into either region I or

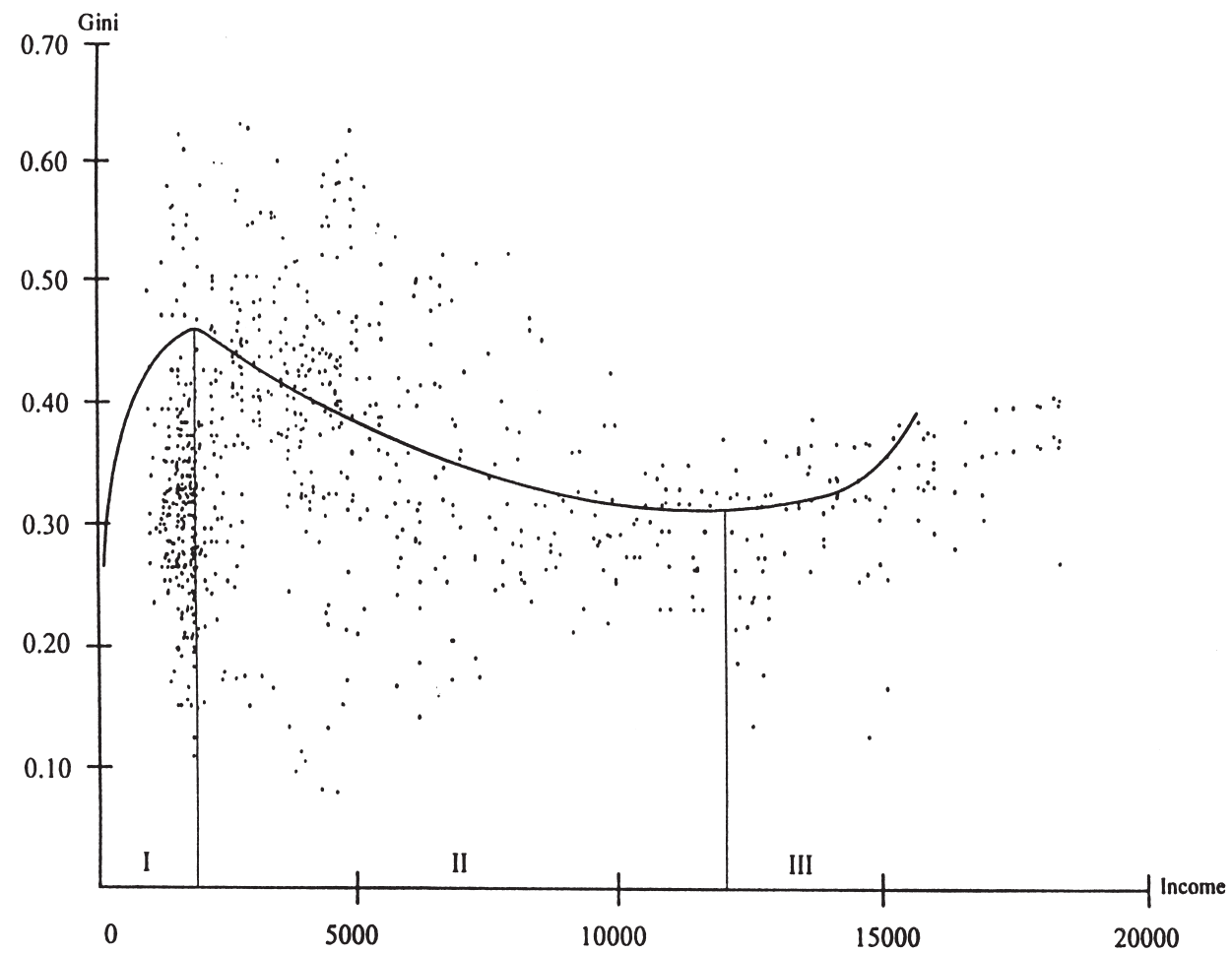

Figure 1. GINI Coefficient and Income Data 
Table 3. Country Location on Kuznets Curve ${ }^{\mathrm{a}}$

\begin{tabular}{lllll}
\hline Region I & & \multicolumn{2}{c}{ Region II } & Region III \\
\hline Ghana & Argentina & El Salvador & Panama & Australia \\
Honduras & Bahamas & Finland & Peru & Canada \\
India & Bangladesh & Greece & Puerto Rico & Denmark \\
Kenya & Belgium & Guatemala & Poland & France \\
Lesotho & Bolivia & Hong Kong & Singapore & Germany, FR \\
Malawi & Botswana & Hungary & Spain & Italy \\
Nepal & Bulgaria & Indonesia & Sri Lanka & Japan \\
Pakistan & Brazil & Iran & Swaziland & Netherlands \\
Senegal & Chile & Ireland & Thailand & Norway \\
Sierra Leone & China & Israel & Trinidad and Tobago & Sweden \\
Tanzania & Colombia & Jamaica & Uruguay & Switzerland \\
Uganda & Costa Rica & Korea, Republic of & USSR & United Kingdom \\
Zambia & Czechoslovakia & Malaysia & Venezuela & United States \\
Zimbabwe & Ecuador & Mexico & Yugoslavia & \\
& Egypt & New Zealand & & \\
\hline
\end{tabular}

${ }^{\text {a }}$ Countries are categorized according to the last year of available data.

region II of the estimated curve, they will encounter either increasing or decreasing income inequality in the future, depending on where they are currently located on the curve. $^{4}$

One explanation for the renewed positive relationship between income inequality and per capita income among higher-developed countries rests on the shift away from a manufacturing base towards a service base in these countries. According to Bishop et al. (1991), given the service sector is characterized by bimodal pay scales, which results from a premium placed on education, a shift towards a service base generates greater dispersion in incomes. This is further supported by Katz and Murphy (1992) and Bound and Johnson (1992), who find that US incomes have diverged since the early 1980s.

\section{Summary}

Our results support much of the recent evidence on the relationship between income inequality and per capita income. We find that for lower-developed to middledeveloped countries, the Kuznets curve is indeed an inverted-U. For higher-developed countries, however, the relationship between income inequality and per capita income becomes positive again. Given that income equity remains an important goal to many policymakers, this result indicates a potentially adverse consequence associated with the most recent stages of the development process.

Although these results are intuitively appealing, they must be qualified in at least one important aspect. Since studies of the Kuznets relationship analyze reduced-form estimates, it is difficult to assign causality. Hence, we cannot directly infer why the relationship between income and income inequality exists. To avoid this causality problem, one could model the system as a series of structural equations and estimate how per capita incomes are related to income inequality, technology, industrial composition, trade patterns, etc. However, owing to data inconsistencies and limitations, similar to 
other studies we used the reduced-form approach. Accordingly, our reduced form estimates of the Kuznets curve provide intuition into the relationship between income levels and income inequality, but it remains unclear how and why this relationship exists. Perhaps, with greater emphasis on collecting new data, future research will uncover the structural link between income and income inequality.

\section{References}

Amos, O., "Unbalanced Regional Growth and Regional Income Inequality in the Latter Stages of Development," Regional Science and Urban Economics 18 (1988):549-66.

Bishop, J., J. Formby, and P. Thistle, "Changes in US Earnings Distributions in the 1980s," Applied Economics 23 (1991):425-34.

Bound, J. and G. Johnson, "Changes in the Structure of Wages in the 1980s: An Evaluation of Alternative Explanations," American Economic Review 82 (1992):371-92.

Cline, W., "Distribution and Development: A Survey of Literature," Journal of Development Economics 1 (1975):359-400.

Cromwell, J., "The Size Distribution of Income: An International Comparison," Review of Income and Wealth 23 (1977):291-308.

Dawson, P., "On Testing Kuznets' Economic Growth Hypothesis," Applied Economics Letters 4 (1997):409-10.

Hausman, J., "Specification Tests in Econometrics," Econometrica 46 (1978):1251-71.

Heston, A. R. Summers, D. Nuxoll, and B. Aten, Penn World Tables v. 5.6, Cambridge, MA: National Bureau of Economic Research, 1995.

Jha, S., "The Kuznets Curve: A Reassessment," World Development 24 (1996):773-80.

Katz, L. and K. Murphy, "Changes in Relative Wages, 1963-87: Supply and Demand Factors," Quarterly Journal of Economics 107 (1992):35-78.

Kuznets, S., "Economic Growth and Income Inequality," American Economic Review 45 (1955):1-28.

Levy, F. and J. Murnane, "US Earnings Levels and Earnings Inequality: A Review of Recent Trends and Proposed Explanations," Journal of Economic Literature 30 (1992):1333-81.

Papanek, G. and O. Kyn, "The Effect on Income Distribution of Development, the Growth Rate and Economic Strategy," Journal of Development Economics 23 (1986):55-65.

Partridge, M., D. Rickman, and W. Levernier, "Trends in US Income Inequality: Evidence from a Panel of States," Quarterly Review of Economics and Finance 36 (1996):17-37.

Ram, R., "Kuznets Inverted-U Hypothesis: Evidence from a Highly Developed Country," Southern Economic Journal 57 (1991):1112-23.

_ straint," Economic Development and Cultural Change 43 (1995):425-32.

— , "Level of Economic Development and Income Inequality: Evidence from the Postwar Developed World," Southern Economic Journal 64 (1997):576-83.

Ravallion, M., "Growth and Poverty: Evidence for Developing Countries in the 1980s," Economics Letters 48 (1995):411-17.

Tabatabai, H., Statistics on Poverty and Income Distribution: An ILO Compendium of Data, Geneva: International Labour Office, 1996.

Tribble, R., "The Kuznets-Lewis Process within the Context of Race and Class in the US Economy," International Advances in Economic Research 2 (1996):151-64.

\section{Notes}

1. In income-inequality/income space, the GINI coefficient is defined as the ratio of the difference between a 45 degree ray from the origin and the Lorenz curve- to the triangle underneath the 45 degree ray. Hence, the GINI coefficient is exactly one half of the relative mean difference, which is defined as the average of the absolute values of differences between all pairs of 
incomes. As such, the GINI coefficient is bounded between 0 and 1, with larger values indicating higher levels of inequality. Although one can readily envision many problems associated with the GINI calculation (see Levy and Murnane (1992) for a summary of the problems), it does provide a basis for comparing cross-country income inequality.

2. Figures for the GINI coefficient were obtained from Tabatabai (1996). Real per capita GDP figures, measured in international dollars at 1985 prices (1985ID), were obtained from Heston et al. (1995).

3. Higher-order terms (up to a quartic) were included in initial regressions. Since they did not significantly affect the character of the regression, and were insignificant at conventional levels, they were excluded.

4. To compare our results with findings from recent studies that estimate the Kuznets curve using developed country data, we ran regressions excluding developing nations (those nations in regions I and II of Figure 1). Results from the estimated panel data models support previous findings that a U-shape characterizes the relationship between income inequality and per capita income, with most developed countries lying on the positively sloped region of the curve. 